\title{
400-nm-Bandwidth Emission From a Cr-Doped Glass Fiber
}

\author{
Jian-Cheng Chen, Yen-Sheng Lin, Cheng-Nan Tsai, Kuang-Yao Huang, Chien-Chih Lai, Wei-Zhi Su, \\ Ren-Chin Shr, Fu-Jen Kao, Tao-Yuan Chang, Senior Member, IEEE, and Sheng-Lung Huang, Senior Member, IEEE
}

\begin{abstract}
Cr}^{4+}$-doped glass fiber by a laser-heated pedestal growth method is reported. By analyzing the absorption spectra, the transitions of $\mathrm{Cr}^{3+}$ and $\mathrm{Cr}^{4+}$ in the fibers are identified. With appropriate pumping wavelength and divalent doping concentration, both $\mathrm{Cr}^{3+}$ and $\mathrm{Cr}^{4+}$ emission bands can be excited simultaneously, and become comparable in their fluorescent intensities. As a result, more than 400-nm-width emission peaked at $1144 \mathrm{~nm}$ was generated at room temperature. As much as $12 \mu \mathrm{W}$ of amplified spontaneous emission was obtained by pumping with a 900-nm Ti : sapphire laser.
\end{abstract}

Index Terms-Fluorescence spectroscopy, infrared spectroscopy, light sources, optical fiber devices, transition metal compounds.

\section{INTRODUCTION}

$\mathbf{N}$ EAR-INFRARED (NIR) broadband light sources demonstrated in $\mathrm{Cr}^{4+}$-doped crystals, such as forsterite [1]-[3] and YAG [3]-[5], are of great interest for developing tunable solid-state lasers, fiber amplifiers in optical communication systems, and optical coherence tomography (OCT) in biomedics [6]. It is well known that the broad emission of tetrahedrally coordinated $\mathrm{Cr}^{4+}$-doped materials is attributed to the coupling between the electronic levels of $3 \mathrm{~d}$ electrons with lattice vibrations. The search for $\mathrm{Cr}^{4+}$-activated gain materials has been expanded from crystalline to glass hosts. However, $\mathrm{Cr}$ ions are likely to exist in the stable form of +3 oxidation state and hardly found in the tetravalent coordination state in normal glasses. The stable +4 oxidation state of $\mathrm{Cr}$ ions has been found in aluminate, alumino-silicate, and gallate glasses [7], although they still suffer from poor emission efficiency [8]. Therefore, the choice of glass compositions for $\mathrm{Cr}$-doped materials is of critical importance, and has been investigated in recent years [7], [9]-[11]. The first $\mathrm{Cr}^{4+}$-doped silica-based optical fiber was fabricated by the modified chemical vapor deposition (MCVD) method [12]. The emission peak was at $1250 \mathrm{~nm}$ with

Manuscript received January 4, 2007; revised February 13, 2007. This work was supported in part by the Ministry of Education Program for Promoting Academic Excellence of Universities under Grant 91-E-FA08-1-4.

J.-C. Chen, C.-N. Tsai, K.-Y. Huang, W.-Z. Su, R.-C. Shr, and T.-Y. Chang are with the Institute of Electro-Optical Engineering, National Sun Yat-Sen University, Kaohsiung, Taiwan 804, R.O.C.

Y.-S. Lin and C.-C. Lai are with the Graduate Institute of Electro-Optical Engineering, National Taiwan University, Taipei, Taiwan 106, R.O.C.

F.-J. Kao is with the Institute of Biophotonics Engineering, National YangMing University, Taipei, Taiwan 112, R.O.C.

S.-L. Huang is with the Graduate Institute of Electro-Optical Engineering, National Taiwan University, Taipei, Taiwan, R.O.C. He is also with the Department of Electrical Engineering, National Taiwan University, Taipei, Taiwan 106, R.O.C. (e-mail: slhuang@cc.ee.ntu.edu.tw).

Color versions of one or more of the figures in this letter are available online at http://ieeexplore.ieee.org.

Digital Object Identifier 10.1109/LPT.2007.894322 500-nm bandwidth under 860- to 980-nm excitation. However, it can only be operated at low temperature around $77 \mathrm{~K}$. Another study also using the MCVD method found that the fibers doped with aluminum and gallium exhibit a 300-nm emission band of $\mathrm{Cr}^{4+}$ ions at $1100 \mathrm{~nm}$ at room temperature [13], [14]. After annealing around $1000{ }^{\circ} \mathrm{C}$, the emission spectrum became stronger and transfers to a peak in 790- to $880-\mathrm{nm}$ range with a width of approximately $200 \mathrm{~nm}$, which is attributed to the transition of $\mathrm{Cr}^{3+}$. In our previous study, it was found that both $\mathrm{Cr}^{3+}$ and $\mathrm{Cr}^{4+}$ ions are coexistent in the YAG-silica diffusion layer of double-clad $\mathrm{Cr}^{4+}$ : YAG crystal fiber. In this study, with a well controlled growth condition to make the $\mathrm{SiO}_{2}$ entirely diffuses into YAG as the core, the $\mathrm{Cr}^{4+}$-doped glass fiber with $\mathrm{SiO}_{2}$-cladding by the laser-heated pedestal growth method was fabricated. The absorption spectrum by multipeak Gaussian fitting, and the pumping wavelength dependence of emission spectra were investigated at room temperature.

\section{EXPERIMENT}

$\mathrm{A} \mathrm{Cr}^{4+}$ : YAG crystal fiber with $66 \mu \mathrm{m}$ in diameter was grown from a 0.5-mol.\% doped $\mathrm{Cr}^{4+}$ : YAG with $\langle 111\rangle$ in crystal orientation and $500 \mu \mathrm{m} \times 500 \mu \mathrm{m}$ in cross section. The grown crystal fiber was then inserted into a fused-silica capillary tube for redrawing. The silica diffuses into the $\mathrm{Cr}^{4+}$ : YAG during redrawing to form the core of the $\mathrm{Cr}^{4+}$-doped glass fiber. The diameters of core and cladding are 90 and $320 \mu \mathrm{m}$, respectively. Fig. 1 shows the distributions of fiber compositions, which were measured by an electron probe microanalyzer [(EPMA) JXA8900R, JEOL]. The composition of the cladding is $\mathrm{SiO}_{2}$, while the core consists of $\mathrm{Y}_{2} \mathrm{O}_{3}, \mathrm{Al}_{2} \mathrm{O}_{3}$, and $\mathrm{SiO}_{2}$. The concentration of $\mathrm{Y}_{2} \mathrm{O}_{3}$ is about $38 \mathrm{wt} . \%$ in the whole core area, while that of $\mathrm{Al}_{2} \mathrm{O}_{3}$ and $\mathrm{SiO}_{2}$ is a function of position with average concentrations of 29 and $33 \mathrm{wt} . \%$, respectively.

The absorption spectra were measured using a halogen-tungsten lamp and the signal was detected by spectrometers in visible and NIR ranges separately. The emission spectra were excited using a tunable Ti:sapphire laser (Tsunami-3950, Spectra-Physics) with a tuning range of $750-1000 \mathrm{~nm}$. The signal was collected using a $50 / 125-\mu \mathrm{m}$ multimode fiber by butt-coupling.

\section{RESUlt AND DisCUSSION}

Fig. 2(a) shows the three absorption spectra with different concentrations of $\mathrm{Cr}_{2} \mathrm{O}_{3}$ and $\mathrm{CaO}$. The doping concentrations were controlled by E-gun deposition of $\mathrm{Cr}_{2} \mathrm{O}_{3}$ and $\mathrm{CaO}$ thin-film layers on the circumference of $66-\mu \mathrm{m} \mathrm{Cr}{ }^{4+}$ : YAG crystal fibers. All three samples show similar absorption properties in the visible region with two apparent peaks at 453 and $650 \mathrm{~nm}$, which were also found in silicate glasses [9], [16]. 


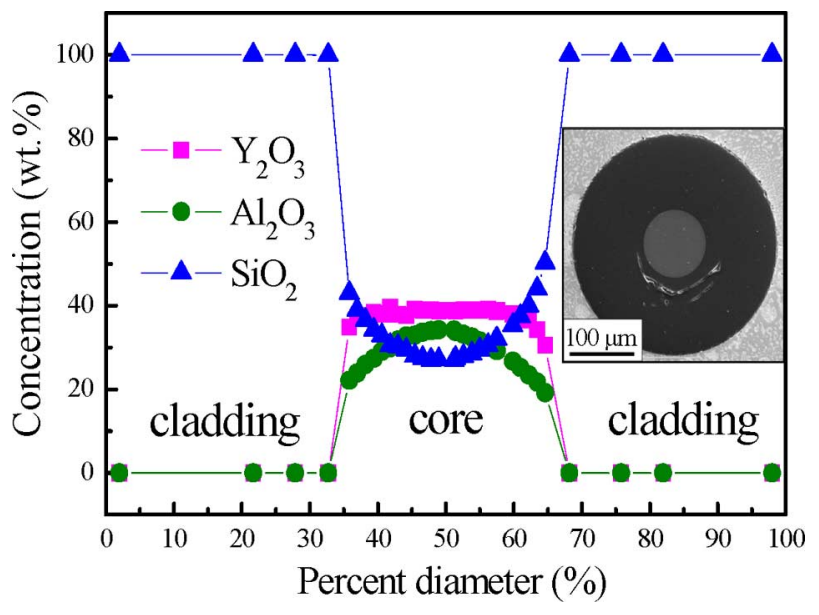

Fig. 1. Distributions of host compositions by EPMA measurement. The inset shows the end view of the $\mathrm{Cr}^{4+}$-doped glass fiber.

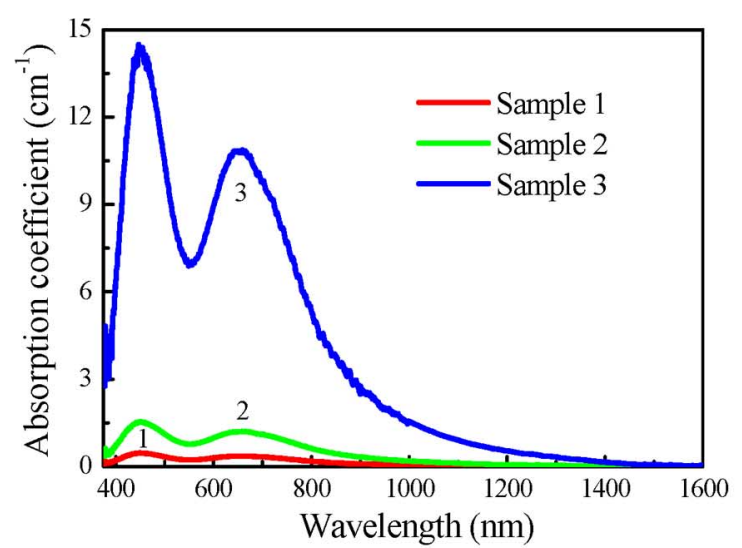

(a)

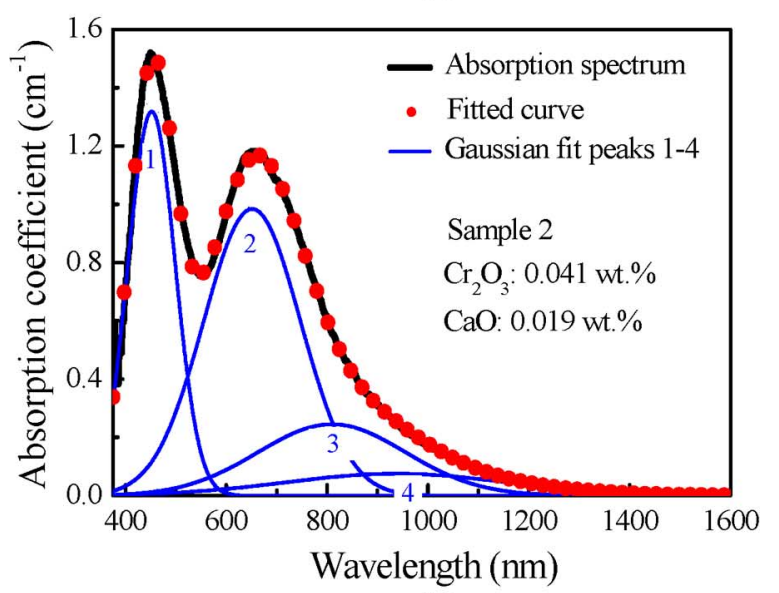

(b)

Fig. 2. (a) Absorption spectra, and (b) the multipeak Gaussian fitting of Sample 2.

The corresponding absorption coefficient is almost linearly proportional to the concentration of $\mathrm{Cr}_{2} \mathrm{O}_{3}$. However, when the concentration of $\mathrm{CaO}$ increases to $0.419 \mathrm{wt} \%$, the absorption spectrum extends to $1400 \mathrm{~nm}$. Here, the multi-Gaussian peaks were fitted to identify the transitions in the $\mathrm{Cr}^{4+}$-doped glass fiber. Sample 1 was made from a pure YAG core only with $\mathrm{Cr}_{2} \mathrm{O}_{3}$ doping. The absorption spectrum is well fitted
TABLE I

IDENTIFIED Transitions OF THE THREE SAMPLES UsING MUlTIPEAK GAUSSIAN FITTING

\begin{tabular}{ccccc}
\hline \hline $\begin{array}{c}\text { Sample } \\
\text { number }\end{array}$ & $\begin{array}{c}\text { Dopant } \\
\text { concentrations } \\
(\text { wt.\% })\end{array}$ & $\begin{array}{c}\text { Peak } \\
(\mathrm{nm})\end{array}$ & $\begin{array}{c}\text { Bandwidth } \\
(\mathrm{nm})\end{array}$ & Oxidation states \\
\hline \multirow{2}{*}{1} & $\mathrm{Cr}_{2} \mathrm{O}_{3}: 0.013$ & 453 & 89 & $\mathrm{Cr}^{3+}$ \\
& $\mathrm{CaO}: 0$ & 650 & 188 & $\mathrm{Cr}^{3+}$ \\
& & 810 & 300 & $\mathrm{Cr}^{3+}$ \\
\hline \multirow{2}{*}{2} & $\mathrm{Cr}_{2} \mathrm{O}_{3}: 0.041$ & 651 & 191 & $\mathrm{Cr}^{3+}$ \\
& $\mathrm{CaO}^{3+} 0.019$ & 809 & 292 & $\mathrm{Cr}^{3+}$ \\
& & 938 & 437 & $\mathrm{Cr}^{3+}$ \\
& & 453 & 87 & $\mathrm{Cr}^{4+}$ \\
\hline \multirow{2}{*}{3} & $\mathrm{Cr}_{2} \mathrm{O}_{3}: 0.408$ & 651 & 190 & $\mathrm{Cr}^{3+}$ \\
& $\mathrm{CaO}^{3+} 0.419$ & 810 & 293 & $\mathrm{Cr}^{3+}$ \\
& & 982 & 496 & $\mathrm{Cr}^{3+}$ \\
\hline \hline
\end{tabular}

by three Gaussian waveforms with peaks at 453, 650, and $810 \mathrm{~nm}$, which are attributed to the $\mathrm{Cr}^{3+}$ ions with transitions of ${ }^{4} \mathrm{~A}_{2}$ to ${ }^{4} \mathrm{~T}_{1}$ and ${ }^{4} \mathrm{~T}_{2}$. As shown in Fig. 2(b), in addition to these three peaks, Sample 2 with a doping of $\mathrm{CaO}$ showed an absorption peak at $938 \mathrm{~nm}$ with a bandwidth of $437 \mathrm{~nm}$. Similarly, Sample 3 showed an absorption peak at $982 \mathrm{~nm}$ with a bandwidth of $496 \mathrm{~nm}$. The broad absorption band from 600 to $1400 \mathrm{~nm}$ has been assigned to the transition from $\mathrm{Cr}^{4+}$ ion in alumino-silicate glasses [7], [8], [16]. The multipeak fitting for the absorption spectra in these three samples is summarized in Table I. Assuming the $\mathrm{Cr}$ ions only exist in +3 and +4 oxidation states, the ratio of $\mathrm{Cr}^{4+}$ to total $\mathrm{Cr}$ in Samples 2 and 3 can be estimated by comparing the area of absorption peak and concentration of $\mathrm{Cr}_{2} \mathrm{O}_{3}$ by EPMA measurement. The estimated ratio of $\mathrm{Cr}^{4+}$ to total $\mathrm{Cr}$ in Samples 2 and 3 are $1.5 \%$ and $11.1 \%$, respectively.

As a result of the absorption bands of $\mathrm{Cr}^{3+}$ and $\mathrm{Cr}^{4+}$ ions overlapped in the NIR region, a tunable $\mathrm{Ti}$ : sapphire laser was used to measure the emission spectra. Sample 1 shows a typical $\mathrm{Cr}^{3+}$ emission spectrum in silicate glass with a peak around $950 \mathrm{~nm}$ when pumping wavelengths are between 750 and $800 \mathrm{~nm}$. The emission bands have a width of approximated $250 \mathrm{~nm}$ and a long-wavelength tail up to $1300 \mathrm{~nm}$. The emission spectra of Sample 2 show red shift by increasing the pumping wavelength. It reveals an apparent peak around $1000 \mathrm{~nm}$ when pumping wavelengths are between 750 and $800 \mathrm{~nm}$. When longer than $900 \mathrm{~nm}$, the emission peak shifts toward $1150 \mathrm{~nm}$ and a broad emission band from 1250 to $1600 \mathrm{~nm}$ is generated. It is apparent that it is composed of both the $\mathrm{Cr}^{3+}$ and $\mathrm{Cr}^{4+}$ emissions. The emission spectra of Sample 3 always showed a peak at $1230 \mathrm{~nm}$ with a bandwidth of $340 \mathrm{~nm}$. When pumping at a shorter wavelength, the generation of $\mathrm{Cr}^{3+}$ fluorescence is reabsorbed by $\mathrm{Cr}^{4+}$ ion and results in the emission at $1230 \mathrm{~nm}$, while for pumping at a longer wavelength, only $\mathrm{Cr}^{4+}$ ions can be excited.

Therefore, only Sample 2 generated a combined emission from $\mathrm{Cr}^{3+}$ and $\mathrm{Cr}^{4+}$ ions. Fig. 3 shows the pumping wavelength dependence of emission peaks and bandwidths of Sample 2. The emission peaks shift from 1008 to $1144 \mathrm{~nm}$, while the bandwidth increases from 268 to $406 \mathrm{~nm}$ when increasing pumping wavelength from 750 to $900 \mathrm{~nm}$. It is interesting to note that with a pumping wavelength at $900 \mathrm{~nm}$, both $\mathrm{Cr}^{3+}$ and $\mathrm{Cr}^{4+}$ emission bands can be excited and become comparable 


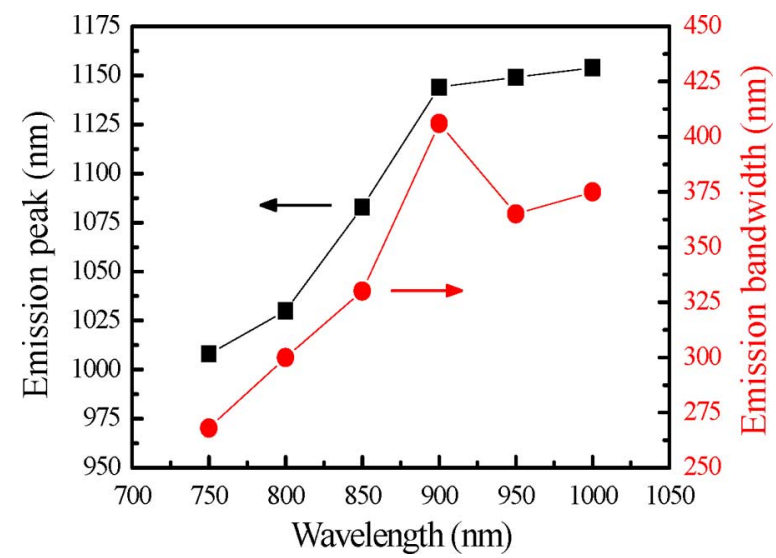

Fig. 3. Excitation wavelength dependence of emission peaks and bandwidths of Sample 2.

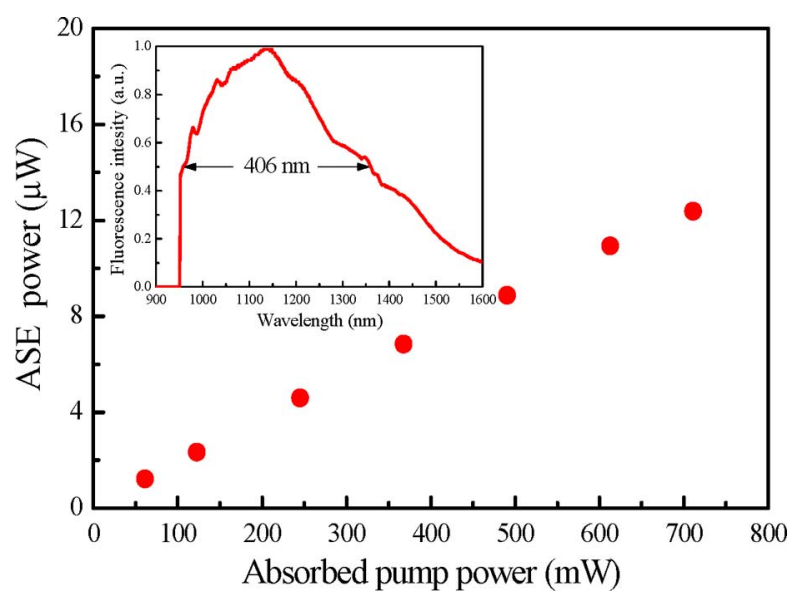

Fig. 4. Measured ASE output power of Sample 2. The inset is the fluorescence spectrum by $900-\mathrm{nm}$ pumping. The pumping light was filtered with a $950-\mathrm{nm}$ long-wavelength-pass filter.

in their intensities to generate the 406-nm broadband emission. In Fig. 4, the power of the amplified spontaneous emission (ASE) was measured. The inset is the corresponding spectrum by using a 950-nm-long wavelength-pass filter to block the pumping power. As much as $12 \mu \mathrm{W}$ of the ASE power was obtained, which was limited by the output power of the $\mathrm{Ti}$ : sapphire laser. It should be noted here that our reflected fluorescence measurement showed that the 3-dB bandwidth of the spontaneous emission was about $483 \mathrm{~nm}$ centered around $1050 \mathrm{~nm}$, but its power level was low. According to our simulation, the excited-state absorption cross section is typically less than $20 \%$ of the emission cross section. To our knowledge, it is the first report that ASE power with more than 400-nm bandwidth in Cr-doped glass fiber has ever been generated at room temperature. It may be a candidate as a light source for a high-resolution and high-penetration depth OCT system.

\section{CONCLUSION}

The red shift of $\mathrm{Cr}^{3+}$ fluorescence and blue shift of $\mathrm{Cr}^{4+}$ fluorescence in $\mathrm{Cr}$-doped fiber make it possible to form very broadband NIR emission. By the analysis of absorption spectra with multipeak Gaussian fitting, it was found that the absorption peaks at 453,650 , and $810 \mathrm{~nm}$ are a transition from $\mathrm{Cr}^{3+}$ ions, while that at around $960 \mathrm{~nm}$ is the transition from $\mathrm{Cr}^{4+}$ ions. With an appropriate pumping wavelength and $\mathrm{CaO}$ doping concentration, both $\mathrm{Cr}^{3+}$ and $\mathrm{Cr}^{4+}$ emission bands can be excited simultaneously, and become comparable in their fluorescent intensities to generate more than $400-\mathrm{nm}$ emission peaked at $1144 \mathrm{~nm}$.

\section{REFERENCES}

[1] A. McWilliam, A. A. Lagatsky, C. G. Leburn, P. Fischer, C. T. A. Brown, G. J. Valentine, A. J. Kemp, S. Calvez, D. Burns, M. D. Dawson, M. Pessa, and W. Sibbett, "Low-loss GaInNAs saturable Bragg reflector for mode-locking of a femtosecond $\mathrm{Cr}^{4+}$ : Forsterite-laser," IEEE Photon. Technol. Lett., vol. 17, no. 11, pp. 2292-2294, Nov. 2005.

[2] T. Fujii, M. Nagano, and K. Nemoto, "Spectroscopic and laser oscillation characteristics of highly $\mathrm{Cr}^{4+}$-doped forsterite," IEEE J. Quantum Electron., vol. 32, no. 8, pp. 1497-1503, Aug. 1996.

[3] C. R. Pollock, D. B. Barber, J. L. Mass, and S. Markgraf, " $\mathrm{Cr}^{4+}$ lasers: Present performance and prospects for new host lattices," IEEE J. Sel. Topics Quantum Electron., vol. 1, no. 1, pp. 62-66, Apr. 1995.

[4] C. Y. Lo, K. Y. Huang, J. C. Chen, S. Y. Tu, and S. L. Huang, "Glassclad $\mathrm{Cr}^{4+}$ : YAG crystal fiber for the generation of superwideband amplified spontaneous emission," Opt. Lett., vol. 29, pp. 439-441, Mar. 2004.

[5] C. Y. Lo, K. Y. Huang, J. C. Chen, C. Y. Chuang, C. C. Lai, S. L. Huang, Y. S. Lin, and P. S. Yeh, "Double-clad $\mathrm{Cr}^{4+}$ : YAG crystal fiber amplifier," Opt. Lett., vol. 30, pp. 129-131, Jan. 2005.

[6] M. Rossetti, L. Li, A. Fiore, L. Occhi, C. Velez, S. Mikhrin, and A. Kovsh, "High-power quantum-dot superluminescent diodes with p-doped active region," IEEE Photon. Technol. Lett., vol. 18, no. 18 , pp. 1946-1948, Sep. 15, 2006.

[7] T. Murata, M. Torisaka, H. Takebe, and K. Morinaga, "Compositional dependence of the valency state of $\mathrm{Cr}$ ions in oxide glasses," J. NonCryst. Solids, vol. 220, pp. 139-146, 1997.

[8] X. Feng and S. Tanabe, "Spectroscopy and crystal-field analysis for $\mathrm{Cr}(\mathrm{IV})$ in alumino-silicate glasses," Opt. Mater., vol. 20, pp. 63-72, 2002.

[9] X. Wu, H. Yuan, W. M. Yen, and B. G. Aitken, "Compositional dependence of the luminescence from $\mathrm{Cr}^{4+}$-doped calcium aluminate glass," J. Lumin., vol. 66\&67, pp. 285-289, 1996.

[10] H. Yamazaki and S. Tanabe, "Compositional dependence of fluorescence spectra of $\mathrm{Cr}^{3+} / \mathrm{Cr}^{4+}$-doped calcium alumino-silicate glasses for broadband telecommunication," Jpn. J. Appl. Phys., vol. 44, pp. 5011-5013, 2005.

[11] J. C. Chen, K. Y. Huang, C. N. Tsai, Y. S. Lin, C. C. Lai, G. Y. Liu, F. J. Kao, S. L. Huang, C. Y. Lo, Y. S. Lin, and P. Shen, "Composition dependence of the micro-spectroscopy of Cr ions in double-clad Cr:YAG crystal fiber," J. Appl. Phys., vol. 99, pp. 093113-093117, May 2006.

[12] V. Felice, B. Dussardier, J. K. Jones, G. Monnom, and D. B. Ostrowsky, " $\mathrm{Cr}^{4+}$-doped silica optical fibers: Absorption and fluorescence properties," Eur. Phys. J. AP, vol. 11, pp. 107-110, 2000.

[13] V. V. Dvoyrin, E. M. Dianov, V. M. Mashinsky, V. B. Neustruev, A. N. Guryanov, A. Y. Laptev, A. A. Umnikov, M. V. Yashkov, and N. S. Vorobev, "Absorption and luminescence properties of $\mathrm{Cr}^{4+}$-doped silica fibers," Quantum Electron., vol. 31, pp. 996-998, 2001.

[14] V. V. Dvoyrin, V. M. Mashinsky, V. B. Neustruev, E. M. Dianov, A. N. Guryanov, and A. A. Umnikov, "Effective room-temperature luminescence in annealed chromium-doped silicate optical fibers," J. Opt. Soc. Amer. B, vol. 20, pp. 280-283, Feb. 2003.

[15] V. Felice, B. Dussardier, J. K. Jones, G. Monnom, and D. B. Ostrowsky, "Chromium-doped silica optical fibers: Influence of the core composition on the Cr oxidation states and crystal field," Opt. Mater., vol. 16, pp. 269-277, 2001.

[16] U. Hömmerich, H. Eilers, W. M. Yen, J. S. Hayden, and M. K. Aston, "Near infrared emission at $1.35 \mu \mathrm{m}$ in Cr doped glass," J. Lumin., vol. 60\&61, pp. 119-122, 1994. 